\title{
Unasked Questions and Policy Applications of Foresight: Interview with Leon Fuerth
}

In this interview with Aidan Eyakuze, Prof. Leon Fuerth shares some of his ideas regarding the application of foresight to development challenges and in particular, its relevance now. Sharing experiences drawn from a long life as a public servant and academic he reminds us that the boundaries between foresight and policy are still poorly explored and explosively controversial and that we need to be aware of the all too human temptation to twist the facts to suit the agendas that are being pursued. He exhorts us to work towards finding common ground between the poor and the wealthy given the fact that we are now facing stark choices for an indefinite future. Whether mankind as a whole will be able to overcome the current challenges we face as a species is dependent on our being able to mature to a point where we can manage the consequences of our behavior by anticipating, monitoring and governing our actions - hence a role for foresight.

SID: Professor, thank you for accepting SID's invitation to reflect on the utility of foresight in policymaking. Given your experience at the highest levels of the US government, we are very happy that you spared a moment to reflect on the value of foresight for policymaking.

LF: Thank you for the invitation to contribute to SID's ongoing series on pro-poor foresight. I accepted because of the professional rigour and merit of SID's work, but also for a very personal reason: to honour in a small way, the memory of my late friend Dr David Jhirad, who deeply believed that foresight could be used to further the cause of improving the circumstances of the poor.

In October 2009, acting as the Rockefeller Foundation's Vice President for Research and Evaluation, David made pro-poor applications of foresight the theme of an international meeting of experts at the Foundation's conference centre in Bellagio, Italy. Attendees were primarily experts and activists from developing countries, geographically dispersed so as to be as representative as possible of opinion in the developing world.

I was invited because of my interest in the concept of anticipatory governance ('Forward Engagement'), which focused on the need to blend foresight and policy, and on practical ways for accomplishing that objective. This work drew on my experience as a senior policymaker in the United States government, and on subsequent years of research and teaching to explore foresight both as theory and applied technique. My ideas on the subject were developed in the context of governance in my own country, but David's conference offered me an opportunity for contact with experts whose experiences would be profoundly different than my own. There was also the conference's pro-poor signature. Participation represented a 'stretch' for someone like me, whose background lay in the field of national security. 
SID: What struck you most about the conference on pro-poor applications of foresight that David organized?

LF: There were two ideas that kept on coming to the surface during our discussions in Bellagio. The first idea was a consensus view that poor governance is the most severe obstacle to better lives for people anywhere, but especially in the developing world. The second idea was that the hallmark of good governance, is attention to the long-term future, and to the quality of decisionmaking in the immediate present as a major factor in the quality of the ultimate outcomes.

SID: You recently read one of SID's reports entitled 'Dispatches from the Frontline - Using Pro-poor Foresight to Influence Decision-Making' which asked among other questions how foresight had influenced policy and what lessons and observations could be drawn from the experiences of a global group of foresight practitioners. What did you make of it?

LF: SID has already devoted a major effort to the study of foresight as theory, and I am delighted to see that the focal point of your ongoing work is [its] utility. You asked some extremely hard-nosed questions, and it is so tempting to provide stock answers - yes, foresight is today a profoundly strong influence in decision-making; yes, policy makers are accepting of what foresight can do to help them make decisions, and yes, foresight is naturally tunable to the needs of the poorest'. Not!

I wanted to share with you some answers from my own experience in the Real World. The choice of a military metaphor for SID's report - the Frontline - implies an ongoing battle, and that is profoundly right. The boundaries between foresight and policy are still poorly explored and explosively controversial.

SID: Is foresight largely ineffective in influencing policy, or is there too little documentation to form an answer?

LF: I can't resist observing how artfully this question is pitched: is foresight the failure that it seems to be, or is that just a distorted perception that would yield to more numerous case studies? Foresight is not ineffective, but it is far from having the impact that it might have, and which it deserves even now. The main problem is not academic but political. Foresight is often hijacked to conceal pre-conceived notions of policy by cloaking them with unearned certitude. Policy processes in government are not detached, cerebral exercises. They are much more like particularly brutal ice-hockey matches.

The objective of foresight, properly used, is to expand the range of possible alternative futures, and to promote careful analysis of these. The objective of the policy 'process' is to win: to knock out opposing concepts; to establish one's personal or institutional views as policy, and then to freeze out all competing alternatives. This is not a problem that can be solved by documentation alone. The reason that foresight is so often unable to influence policy has relatively less to do with the presence or absence of superior information, than it does with the zeal and mendacity of those who do not scruple to smother the truth with data. That's political battle, and it is what goes on at the 'front line'. It is not fated to be a losing battle, but the outcome is never certain and issues of policy are never permanently settled.

SID: Given what you observed in the Clinton White House, and researched at George Washington University what is the experience of decision-makers with using foresight?

LF: Decision-makers attempting to use foresight as a guide to action will find out that it is doublesided. On the one hand, foresight is an excellent way to search for 'unasked questions', representing dangerous blind spots that need to be identified during the policymaking process. On the other hand, foresight is an effort to capture the interaction of forces within complex systems. In complex systems, the fundamental property of decisionmaking is error. Uncertainty and risk are chronic aspects of the human condition. Foresight can help to manage this condition, but should not be trusted to cure it. The trouble is that decision-makers are required to make, and fight for, commitments to particular lines of policy. Foresight can help decision-makers recognize when facts are getting out of alignment with projections. But politics makes it extremely hard for the same persons to change course.

SID: So, how do decision-makers assess the value of foresight in improving their decisions? 
LF: Decision-makers are often likely to value foresight most if they think it can help them deal with ongoing crises. Foresight can doubtless be valuable in the midst of a crisis. But the highest use of foresight is to anticipate what may later end in crisis, if not dealt with. Unfortunately, the further into the future a foreseen event may seem to be, the less likely decision-makers are to deal with it. Exceptions to this rule are great historical contrarians - like Churchill - who were prepared to act against current wisdom, based on initially weak signals of oncoming, major challenge. Typically, decision-makers operating at the 'Frontline' of events will not think it feasible to slow down in order to reflect upon the meaning of faint signals. The only corrective for this is to have policies re-examined in the light of the latest information, so as to give decision-makers the chance to change course. These are 'feedback' systems. Policymakers are well advised to make sure these systems are in place.

SID: What type of foresight and from which sources seems to be the most useful for decisionmakers?

LF: Foresight analytics are developing very rapidly. There are new and increasingly powerful methods for reducing masses of data into coherent interpretations of trends. The problem is not lack of utility, but lack of uptake by policymakers. One of the reasons for this is political. Decision-makers are constantly challenged to provide certainty and to generate confidence. Foresight makers can be as dogmatic and inflexible as anybody else. However, the best of them know that we can only approximate the truth: and that the best service they can offer decision-makers is to encourage mindfulness of alternative outcomes.

There is also a cultural gap between policymakers and foresight producers. The former lack the technical backgrounds needed if they are to fully understand what new analytic techniques are offering. The latter are often inexperienced in policymaking, and do not comprehend what policymakers need to know. Corrections for this can be remarkably straightforward. The relationship between foresight and policy needs to be interactive, and interactivity can be encouraged by designing systems that bring these specialists together.
Interactive games, modelling, role playing and, especially, very well crafted scenarios, are the most effective ways to heighten communication between policymakers and foresight producers. A carefully devised scenario offers decision-makers an experience much like sophisticated flight trainers offer to pilots. The problem is that it is the rare decision-maker who can (or will) spend precious time in this kind of pursuit. More subtly, there is always the question of 'face'. Scenarios - like flight trainers - not only crash and burn, but should be deliberately driven to the point of failure - the better to teach decision-makers the signs and symptoms of failure, and how to recover. But what decision-maker will take the risk of being seen to have suffered a catastrophic loss, even if it is only in a virtual environment? The key may be to imbed foresight analysis in training programmes for those who are marked for leadership.

SID: To what extent, if any, can foresight be used to improve the welfare of the poorest?

LF: The growing gap between the richest and the poorest may be driven by policies that can eventually be changed through politics. In this case, foresight already suggests very basic ways to improve the lot of the poorest: promoting public health; opening access to knowledge; and encouraging economic advancement through training and access to opportunity. The question in that case is how to make effective use of resources. Foresight can be used to improve the processes by which propoor policies are designed, applied, and monitored. This is what I call Anticipatory Governance.

But if the existence of poverty - and especially, the growing gap between the very poor and the wealthy - is the product of forces that are baked into the very structure of economic systems depending upon enterprise, then foresight would suggest that there may be no remedy other than social upheaval. Economic depression, revolution, and war have been effective in the past in achieving social inversions - but at extremely high costs.

Democracy and the rule of law offer the only other way to achieve social transformation by means that are evolutionary. Democracy depends on the general ability of the public to sense where the future really lies, and makers of foresight must be concerned about their ability to speak clearly 
to regular people: not just to decision-makers. The future must be participatory.

Finally, I want to draw your attention to the role of foresight in dealing with an emergent set of very powerful ultra-long range issues which can dramatically influence conditions for entire nations, regions, and even for our species such as climate change, manipulation of biological life, and the creation of sentient machines.

We now have the ability to massively disturb nature, but we lack the ability to fine-tune the results. We also lack the self-restraint needed to control our destructive impulses, not just in the relatively short term of decades, but over very long periods of time: centuries in the case of climate change; millennia in the case of nuclear waste; and unlimited time in the case of species die-off and in the less well recognized case of species creation. In this domain the poorest will experience downsides sooner and more severely. These are forces that will require an increasingly global form of awareness and action. The poorest and the wealthiest must find important areas of consensus.

Foresight can be used to help define the agenda for governance and for politics, by identifying early on alternative futures and the choices that these paths require of us. Choices made in the relatively near term will profoundly influence the indefinite future. Survival will depend on the rapid maturation of humankind to the point where it can manage the consequences of its behaviour by anticipating, monitoring, and governing them. Systematic foresight has a vital role to play in making that possible. 